\title{
Regulation of phosphatidylinositol 3-kinase by polyisoprenyl phosphates in neutrophil-mediated tissue injury
}

\author{
Caroline Bonnans, ${ }^{1}$ Koichi Fukunaga, ${ }^{1}$ Raquel Keledjian, ${ }^{3}$ \\ Nicos A. Petasis, ${ }^{3}$ and Bruce D. Levy ${ }^{1,2}$ \\ 'Department of Medicine and ${ }^{2}$ Center of Experimental Therapeutics and Reperfusion Injury, Brigham and Women's Hospital \\ and Harvard Medical School, Boston, MA 02115 \\ ${ }^{3}$ Department of Chemistry, University of Southern California, CA 90089
}

\begin{abstract}
Neutrophils play a central role in host defense, inflammation, and tissue injury. Recent findings indicate a novel role for polyisoprenyl phosphates (PIPPs) as natural downregulatory signals in neutrophils. The relationship between PIPPs and neutrophil early activating signals, such as phosphoinositides, has not been previously determined. Here, we establish presqualene diphosphate (PSDP) as an endogenous PIPP regulator of phosphatidylinositol 3-kinase ( $\mathrm{PI} 3 \mathrm{~K})$. In human neutrophils, leukotriene $\mathrm{B}_{4}\left(\mathrm{LTB}_{4}\right)$ triggered rapid decreases in PSDP and reciprocal increases in PI3K activity. In addition, PSDP was identified by gas chromatography/mass spectrometry in p110 $\gamma-\mathrm{PI} 3 \mathrm{~K}$ immunoprecipitates obtained $30 \mathrm{~s}$ after $\mathrm{LTB}_{4}$, indicating a physical interaction between PSDP and PI3K in activated neutrophils. Moreover, PSDP (0.4-800 pmol) directly inhibited recombinant human $\mathrm{p} 110 \gamma-\mathrm{PI} 3 \mathrm{~K}$ activity. During an experimental model of lung injury and inflammation, a reciprocal relationship was also present in vivo for lung PSDP and PI3K activity. To investigate its therapeutic potential, we developed a new PSDP structural mimetic that blocked human neutrophil activation and mouse lung PI3K activity and inflammation. Together, our findings indicate that PSDP is an endogenous PI3K inhibitor, and suggest that in inflammatory diseases characterized by excessive neutrophil activation, PIPPs can serve as structural templates in a novel antineutrophil therapeutic strategy to limit tissue injury.
\end{abstract}

CORRESPONDENCE

Bruce D. Levy:

blevy@partners.org
Innate immune responses are essential to host defense, yet if unchecked can lead to tissue injury and illness (1). PMN are the primary initial immune effectors of acute inflammation, and these cells use as many as fifty toxins for microbial killing in phagocytic vacuoles (2). Incomplete closure of phagolysosomes or aberrant extracellular release of reactive oxygen species (ROS), granule components, lipid mediators, hypochlorous acid, and other potentially toxic PMN products to surrounding tissues contribute to injury in several human diseases, including the devastating clinical entities of acute lung injury (ALI) and acute respiratory distress syndrome (ARDS) for which no disease-remitting therapy is currently available (3).

To prevent an overexuberant inflammatory response and limit damage to the host, PMN activation programs need to be tightly

$\overline{\text { The online version of this article contains supplemental material. }}$ controlled (1). Select membrane-derived lipid mediators have recently been described as autacoid regulators of PMN functional responses in acute inflammation (4). One of these classes of antiinflammatory membrane lipids involves isoprenoid metabolism. Immune regulatory roles for isoprenoids are emphasized by the hyper$\mathrm{IgD}$ and periodic fever syndrome that results from low polyisoprenyl phosphate (PIPP) levels secondary to defective mevalonate kinase activity (5). Recently, we identified a novel PIPP signaling pathway in PMN (6). One of its components is presqualene diphosphate (PSDP), present in freshly isolated human PMN in nanomolar quantities at baseline (i.e., $1.7 \mathrm{nmol} / 10^{7}$ cells) (6). PMN exposure to the chemoattractant and secretagogue leukotriene $\mathrm{B}_{4}\left(\mathrm{LTB}_{4}\right)$ initiates transient activation of this PIPP signaling pathway with conversion of PSDP to its monophosphate form, presqualene monophosphate (PSMP). PSDP carries biological 
activity as a potent counterregulatory mediator that prevents ROS generation $(6,7)$. In sharp contrast, PSMP is $>100$-fold less active than PSDP for inhibition $(6,7)$. Thus, incoming positive signals for PMN (e.g., $\mathrm{LTB}_{4}$ ) initiate rapid degradation and inactivation of an inhibitory lipid signal (i.e., PSDP) coincident with cell responses (e.g., ROS generation). PSDP levels quickly return to baseline in a time frame that parallels cellular deactivation. Intracellular targets for PSDP to control PMN activity remain to be elucidated. Select PSDP structural mimetics are also active in vivo, dampening mouse responses to zymosan $\mathrm{A}$-induced peritonitis (8).

In addition to PSDP remodeling, $\mathrm{LTB}_{4}$ also initiates phosphatidylinositol 3-kinase (PI3K) activation in PMN to promote NADPH oxidase assembly and ROS production (9, 10). Phosphoinositide signaling initiated by PI3Ks is a critical early event in PMN responses, such as phagocytosis (11) and chemotaxis (12), and contributes to ALI pathogenesis (13). Because $\mathrm{LTB}_{4}$ initiates PMN PI3K activation and PIPP remodeling, we hypothesized that these signaling events were related in the regulation of PMN responses. Here, we report that PI3K activity and PSDP remodeling are linked during PMN activation and deactivation with direct inhibition of PI3K by PSDP to limit PMN responses and lessen the severity of experimental lung inflammation.

\section{RESULTS AND DISCUSSION PSDP and PI3K regulate $\mathrm{LTB}_{4}$-triggered $\mathrm{O}_{2}{ }^{-}$release by human PMN}

To determine if PSDP and PI3K regulate $\mathrm{LTB}_{4}$-stimulated responses, we exposed freshly isolated human PMN to a new structural PSDP mimetic (Fig. 1 A) or a potent and specific inhibitor of PI3K activity (LY294002) before $\mathrm{LTB}_{4}$. A marked increase in the rate of $\mathrm{O}_{2}{ }^{-}$generation was observed within seconds after $\mathrm{LTB}_{4}$ addition that was transient, slowing considerably by $60 \mathrm{~s}$ (Fig. $1 \mathrm{~B}$ ). The presence of either PSDP mimetic (100 nM) or PI3K inhibitor (3 $\mu \mathrm{M})$ markedly blocked $\mathrm{O}_{2}{ }^{-}$generation. Exposure to $\mathrm{LTB}_{4}(10 \mathrm{~min})$ induced $1.6 \pm 0.3 \mathrm{nmol} \mathrm{O}_{2}^{-} / 10^{6} \mathrm{PMN}$ (as compared with vehicle $\left.0.5 \pm 0.1 \mathrm{nmol} \mathrm{O}_{2}^{-} / 10^{6} \mathrm{PMN} ; \mathrm{P}<0.01\right)$. Both the PSDP mimetic and PI3K inhibitor led to $>50 \%$ inhibition of $\mathrm{LTB}_{4}$-triggered $\mathrm{O}_{2}{ }^{-}$generation $\left(0.8 \pm 0.3 \mathrm{nmol} / 10^{6} \mathrm{PMN}\right.$ and $0.7 \pm 0.2 \mathrm{nmol} / 10^{6} \mathrm{PMN}$, respectively; $\mathrm{P}<0.05$ ) (Fig. $1 \mathrm{C})$. The PSDP mimetic concentration in these experiments (i.e., $100 \mathrm{nM}$ ) was 1,000-fold lower than its critical micellar concentration (CMC) $(\sim 100 \mu \mathrm{M}$; Fig. S1, at http://www. jem.org/cgi/content/full/jem.20052143/DC1). To verify that the observed inhibition was not secondary to micelle formation and sequestration of the lipid agonist $\mathrm{LTB}_{4}$, in the next experiments, there was pretreatment with the mimetic, a wash, and stimulation with $\mathrm{LTB}_{4}$. Although this extra step reduced total ROS generation in response to $\mathrm{LTB}_{4}$, the PSDP mimetic still led to a $>50 \%$ decrease $(71.2 \pm$ $27.7 \%$ inhibition, $n=4)$. Together, these results indicate that human PMN activation by $\mathrm{LTB}_{4}$ is highly dependent on PI3K activity and can be inhibited by a new PSDP structural mimetic.
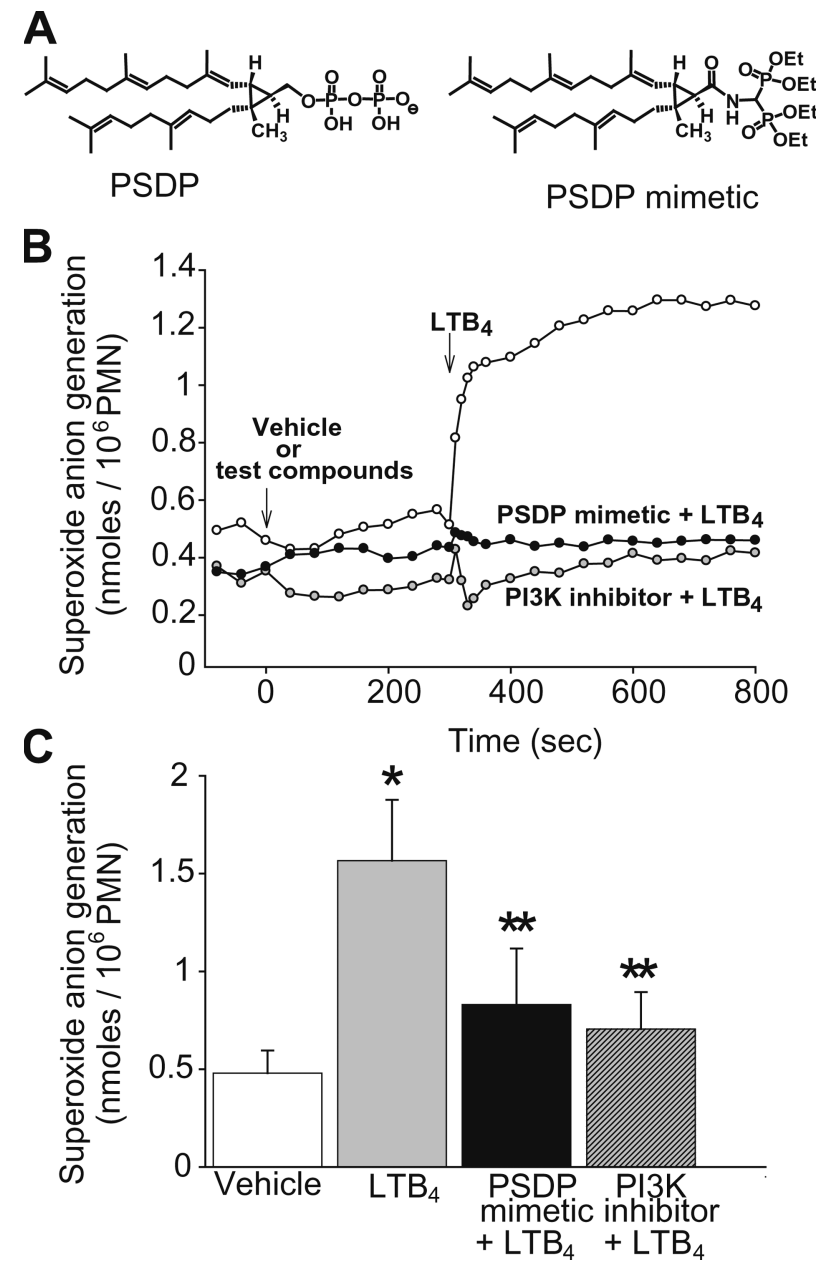

Figure 1. Superoxide anion generation by human $P M N$ is regulated by PI3K and PSDP. (A) Structure of PSDP and a new amido PSDP structural mimetic (CS ChemDraw software). (B) Freshly isolated human PMN were exposed to the PSDP mimetic $(100 \mathrm{nM})(\mathbf{)})$, a PI3K inhibitor $(3 \mu \mathrm{M})(\mathrm{O})$, or vehicle $(\mathrm{O})$ before $\mathrm{LTB}_{4}(100 \mathrm{nM})$ and $\mathrm{O}_{2}{ }^{-}$generation was determined. Results are representative for $n=3$. (C) Total $\mathrm{O}_{2}{ }^{-}$generation was also determined for $\mathrm{LTB}_{4}$-activated PMN (10 $\mathrm{min}$ ) in the presence or absence of the test compounds (mean $\pm \mathrm{SEM}_{i} n=4$ from separate PMN donors; ${ }^{*}, \mathrm{P}<0.01$ as compared with vehicle; ${ }^{* *}, \mathrm{P}<0.05$ as compared with $\mathrm{LTB}_{4}$ ).

\section{Relationship between PI3K activity and PSDP during PMN activation}

To determine if PSDP remodeling and PI3K activation were related, we first examined their kinetics in human PMN after exposure to $\mathrm{LTB}_{4}$. Because $\mathrm{G}$ protein-coupled receptors can activate class IA and IB PI3Ks (10), we measured $\mathrm{PIP}_{3}$ formation in vitro by members of these PI3K classes. After $\mathrm{LTB}_{4}, \mathrm{p} 110 \gamma-\mathrm{PI} 3 \mathrm{~K}$ activity in PMN rapidly increased (within $5 \mathrm{~s}$ ), reached a maximum rate of activity by $20 \mathrm{~s}$, and then declined to basal levels within $30 \mathrm{~s}$ (Fig. 2 A, representative for $n=3$ ). $\mathrm{LTB}_{4}$ also rapidly stimulated p85-based PI3K activity in PMN, but at lower levels than $\mathrm{p} 110 \gamma-\mathrm{PI} 3 \mathrm{~K}$. By $5 \mathrm{~s}$, significant decrements were also evident in total PSDP levels $(7.9 \pm 1.2 \% ; \mathrm{P}<0.01$ ) (see supplemental 

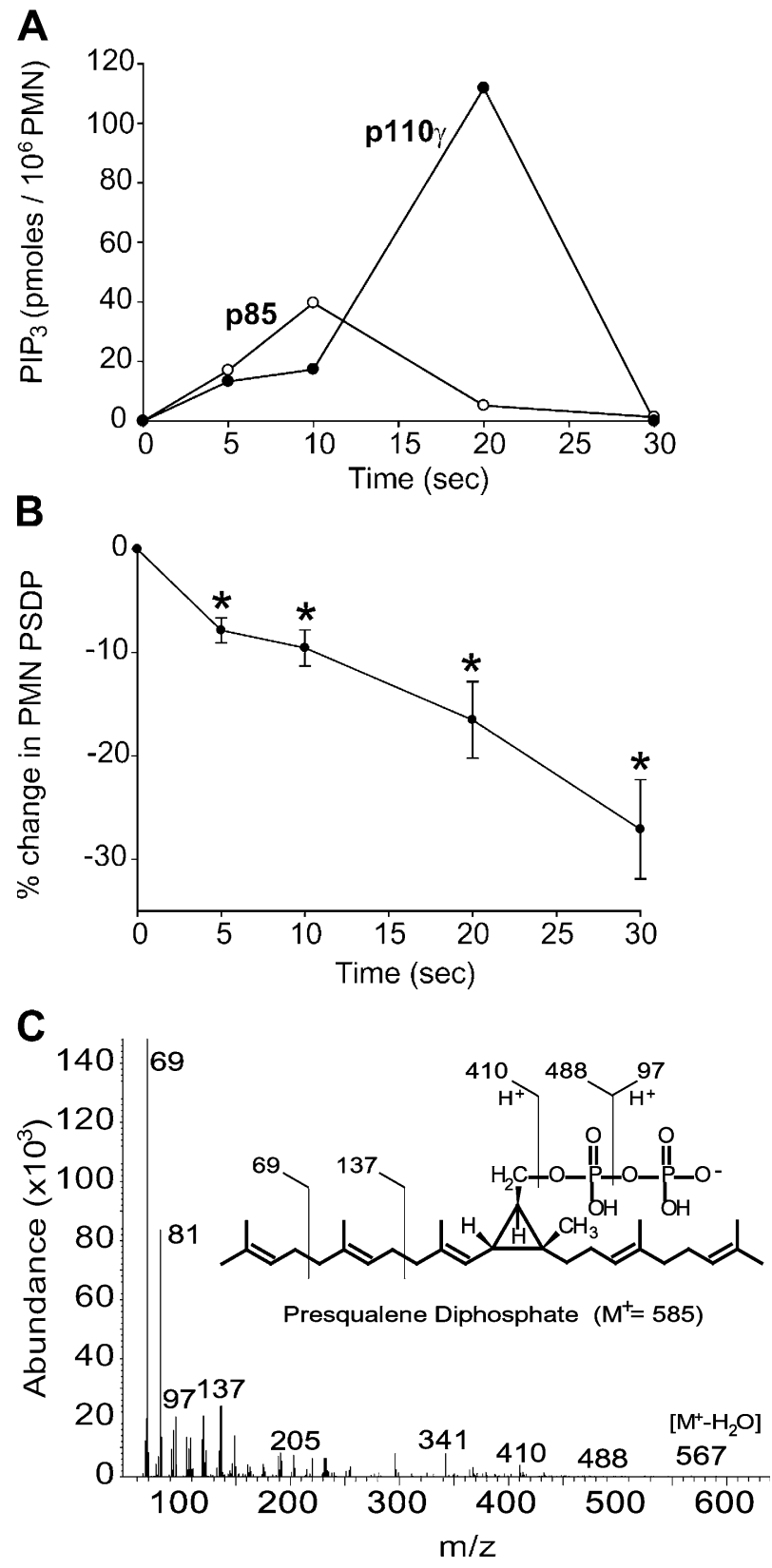

Figure 2. Relationship between PI3K activity and PSDP in activated human PMN. $5 \times 10^{6} \mathrm{PMN}$ were exposed to $100 \mathrm{nM} \mathrm{LTB}_{4}$ and both PI3K activity and PSDP levels were measured at timed intervals. (A) Representative time course $(n=3)$ in PMN lysates for $p 110 \gamma$ and p85-based (O) PI3K activity. (B) PSDP levels in activated PMN were measured in parallel with PI3K. Values reported are the percentage of change in PSDP (mean $\pm \mathrm{SEM} ; n=4,{ }^{*}, \mathrm{P}<0.001$ ). (C) PMN were exposed to $\mathrm{LTB}_{4}\left(100 \mathrm{nM}, 37^{\circ} \mathrm{C}\right)$ for $30 \mathrm{~s}$ and $\mathrm{p} 110 \gamma-\mathrm{PI} 3 \mathrm{~K}$ was isolated by immunoprecipitation with a specific antibody. Lipids were extracted from the immunoprecipitates and taken to GC/MS. lons $(\mathrm{m} / \mathrm{z})$ present in materials bound to $110 \gamma-\mathrm{PI} 3 \mathrm{~K}$ were diagnostic for PSDP as noted in the inset.

Materials and methods, available at http://www.jem.org/ cgi/content/full/jem.20052143/DC1) that progressed to $27.1 \pm 4.8 \%$ reductions $(\mathrm{P}=0.001)$ within $30 \mathrm{~s}$ (Fig. $2 \mathrm{~B})$.
These results indicate that $\mathrm{LTB}_{4}$-triggered activation of $\mathrm{PMN}$ PI3K and PSDP remodeling was concurrent and temporally overlapped with initiation of ROS generation. Although both of these signaling events were rapid in onset, the kinetics for PI3K activation and deactivation differed from the time course for total PSDP remodeling during the initial 30-s interval. To determine if PSDP directly interacted with PI3K as its activity decreased, PMN were exposed to $\mathrm{LTB}_{4}$ for $30 \mathrm{~s}$ and $\mathrm{p} 110 \gamma-\mathrm{PI} 3 \mathrm{~K}$ was immunoprecipitated from cellular materials. Lipid extracts were performed and analyzed by gas chromatography/mass spectrometry (GC/MS) (6). Selective ion monitoring at $\mathrm{m} / \mathrm{z} 137$ (2 isoprenoid units) revealed a unique peak at $18.1 \mathrm{~min}$ in $\mathrm{LTB}_{4}$-exposed PMN extracts. MS spectral diagnostic ions (Fig. 2 C), namely $m / z 567\left[\mathrm{M}^{+}-\right.$ $\left.\left(\mathrm{H}_{2} \mathrm{O}\right)\right], 488\left[\mathrm{M}^{+}-\left(\mathrm{H}_{2} \mathrm{PO}_{4}\right)\right], 410\left[\mathrm{M}^{+}-\left(\mathrm{HP}_{2} \mathrm{O}_{7}\right)\right], 341$ $\left[\mathrm{M}^{+}-\left(\mathrm{HP}_{2} \mathrm{O}_{7}\right)-69\right], 205\left\{\mathrm{M}^{+}-\left[\mathrm{HP}_{2} \mathrm{O}_{7}\right]-69-\right.$ $\left.\left[\mathrm{CH}_{2} \mathrm{C}\left(\mathrm{CH}_{3}\right) \mathrm{CHCH}_{2} \times 2\right]\right\}, 137\left[\mathrm{C}_{10} \mathrm{H}_{17}\right], 97\left[\mathrm{H}_{2} \mathrm{P}_{2} \mathrm{O}_{7}\right]$, $81\left[\mathrm{CH}_{2} \mathrm{C}\left(\mathrm{CH}_{3}\right) \mathrm{CH}\left(\mathrm{CH}_{2}\right)_{2}-\mathrm{H}^{+}\right]$and 69 [base peak; $\left(\mathrm{CH}_{3}\right)_{2} \mathrm{CCHCH}_{2}$, were consistent with authentic PSDP in the PI3K immunoprecipitated material.

\section{Direct inhibition of $\mathrm{p} 110 \gamma-\mathrm{PI} 3 \mathrm{~K}$ by PSDP}

Because PI3K activity and PSDP remodeling were both early signaling events in PMN with interaction between PSDP and p110 $\gamma-\mathrm{PI} 3 \mathrm{~K}$, next we questioned if PSDP could directly regulate PI3K activity. Recombinant human (rh) p110 $\gamma$-PI3K activity was determined by $\mathrm{PIP}_{3}$ formation in vitro in the presence of PSDP, PSMP, or the PI3K inhibitor LY294002. $\mathrm{PIP}_{3}$ formation was significantly decreased by PSDP $(800$ pmol) with $94.7 \pm 5.3 \%$ inhibition $(\mathrm{P}<0.001)$ and a PI3K inhibitor $(500 \mathrm{pmol})$ with $46.7 \pm 6.7 \%$ inhibition $(\mathrm{P}=0.01)$ (Fig. $3 \mathrm{~A}$ ). PSDP inhibited p110 $\gamma-\mathrm{PI} 3 \mathrm{~K}$ in a concentrationdependent fashion (Fig. 3 B). In sharp contrast, PSMP (8-800 pmol) did not significantly impact p110 $\gamma-\mathrm{PI} 3 \mathrm{~K}$ activity. The $\mathrm{IC}_{50}$ for PSDP (38 pmol) had a stoichiometry with PI3K of $\sim 9: 1$. These results indicate that PSDP is a potent direct inhibitor of $\mathrm{p} 110 \gamma-\mathrm{PI} 3 \mathrm{~K}$ with a structure-activity relationship that suggests an important role for the diphosphate structure in PSDP's action on p110 $\gamma-\mathrm{PI} 3 \mathrm{~K}$ activity. The $\mathrm{LTB}_{4}-\mathrm{me}-$ diated PMN remodeling of PSDP corresponds to an $\sim 50$ pmol change in PSDP $/ 10^{6} \mathrm{PMN}$, a decrease that is within the concentration range for regulation of $\mathrm{p} 110 \gamma-\mathrm{PI} 3 \mathrm{~K}$ activity (Fig. 3 B). After cell activation, the percent change in total PSDP (i.e., 28\%) is similar to the change in phosphatidylinositol (17\%) that occurs in activated PMN membranes (14). Collectively, our new findings indicate that receptormediated agonists for PMN remodel PSDP in time-frames and amounts consistent with functional impact on PI3K activity and cellular responses.

\section{PSDP remodeling in vivo during tissue injury and inflammation}

Because PI3K activity occupies a central role in regulating PMN activation during lung injury and inflammation (13), next we determined PSDP remodeling in vivo in mouse lungs during an experimental model of mild ALI secondary 

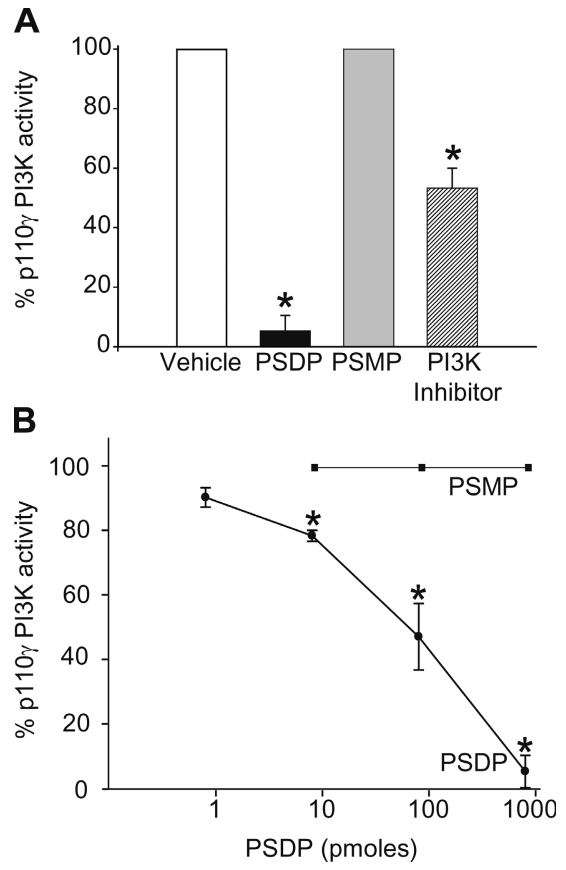

Figure 3. PSDP directly blocked PI3K activity. (A) rhp110 $\gamma$-PI3K activity was determined in the presence or absence of PSDP (800 pmol), PSMP (800 pmol), or a PI3K inhibitor (500 pmol). (B) Concentration response for the impact of PSDP $(\mathbf{)})$ or PSMP $(\mathbf{\square})$ on rhp110 $\gamma$-PI3K activity (mean $\pm \mathrm{SEM} ; n=3 ;{ }^{*}, \mathrm{P}<0.05$ as compared with vehicle).

to aspiration of gastric acid (15), which is a common clinical event (3). To simulate acid aspiration, hydrochloric acid $(\mathrm{HCl})$ (0.1 N, pH $=1.5)$ was selectively instilled into the animals' left lungs (15). Lung PMN infiltration was maximal $12 \mathrm{~h}$ after $\mathrm{HCl}$ injury $\left(14.2 \pm 1.8\right.$ vs. $5.5 \pm 0.8 \times 10^{4} \mathrm{PMN} / \mathrm{mg}$ lung; $\mathrm{P}<0.01$ ) (Fig. 4 A). Expression of class IA and IB PI3Ks in mouse lungs were both increased at 2 and $12 \mathrm{~h}$ after $\mathrm{HCl}$ (Fig. 4 B). Lungs were removed and lipid extracts were prepared for PSDP determination. Of interest, despite increased PMN numbers, PSDP levels were significantly lower in the left lungs of HCl-injured mice $(4.6 \pm 0.3 \mu \mathrm{g}$ PSDP vs. $9.0 \pm$ $1.6 \mu \mathrm{g}$ PSDP in control lungs; $\mathrm{P}<0.02)$. These results indicate that experimental lung injury led to decrements in PSDP concomitant with increased PMN, suggesting an inverse relationship in vivo between lung PSDP and inflammation.

\section{PSDP mimetic blocks PMN infiltration and PI3K activity}

To determine if PSDP can block pulmonary inflammation and PI3K in vivo, we administered a PSDP structural mimetic (0.8 $\mu \mathrm{g} /$ mouse, i.v.) or vehicle $15 \mathrm{~min}$ before $\mathrm{HCl}$ instillation into the left main-stem bronchus. PSDP markedly reduced lung PMN $12 \mathrm{~h}$ after injury (Fig. 5 A). Tissue morphometry on LY-6G-stained histological sections (for identification of mouse PMN) revealed significant inhibition with the PSDP mimetic $(46.8 \pm 7.1 \%$ LY-6G staining $[\mathrm{HCl}]$ vs. $18.8 \pm 5.8 \%$ LY-6G staining [ $\mathrm{HCl}$ plus PSDP mimetic]; $\mathrm{P}<0.05$ ) (Fig. $5 \mathrm{~B})$. In view of the prominent class IA PI3K lung expression
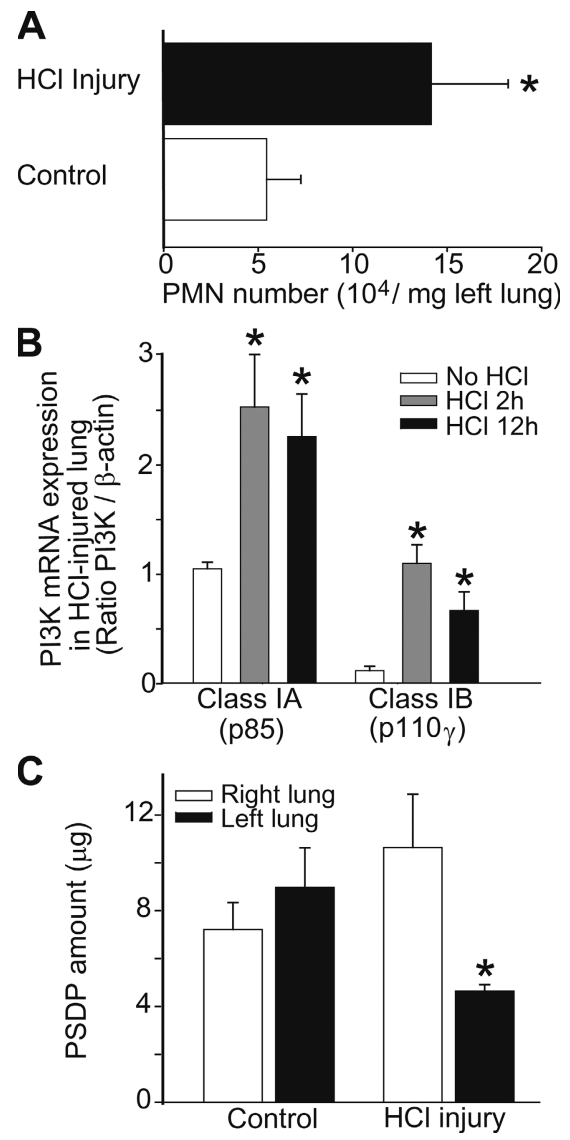

Figure 4. $\mathrm{ALI}$ induced $\mathrm{PMN}$ infiltration, $\mathrm{PI} 3 \mathrm{~K}$, and $\mathrm{PSDP}$ remodeling. (A) $12 \mathrm{~h}$ after $\mathrm{HCl}$-initiated ALI, PMN accumulation was determined by MPO activity in lung homogenates $\left(n=5 ;{ }^{*}, P=0.002\right)$. (B) Semiquantitative RT-PCR for $p 85$ and $p 110 \gamma-P 13 K$ mRNA expression in the injured lungs 2 and $12 \mathrm{~h}$ after $\mathrm{HCl}$ instillation ( $\left.n=3 ;{ }^{*}, \mathrm{P}<0.05\right)$.

(C) PSDP levels were measured in lung lipid extracts with or without $\mathrm{HCl}$-initiated injury $\left(12 \mathrm{~h}\right.$; mean $\left.\pm \mathrm{SEM} ; n=3-4 ;{ }^{*}, \mathrm{P}<0.05\right)$.

that increased markedly after ALI (Fig. 4 B), we next determined class IA PI3K activity after acid injury in the presence or absence of the PSDP mimetic. $\mathrm{HCl}$ injury induced significant increases in lung PI3K activity in p85 immunoprecipitates $\left(0.59 \pm 0.17 \mathrm{PIP}_{3} / \mathrm{mg}\right.$ lung with $\mathrm{HCl}$ vs. $0.05 \pm 0.02$ pmol $\mathrm{PIP}_{3} / \mathrm{mg}$ lung with PBS; $\left.\mathrm{P}<0.05\right)$. Administration of the PSDP mimetic blocked the $\mathrm{HCl}$-induced increase in class IA PI3K activity to near basal levels $(0.05 \pm 0.01 \mathrm{pmol}$ $\mathrm{PIP}_{3} / \mathrm{mg}$ lung; $\mathrm{P}<0.05$ ) (Fig. $5 \mathrm{C}$ ). Thus, PSDP can regulate PMN activation, tissue accumulation, and total PI3K activity in vivo during experimental acid-initiated ALI.

During acute inflammation, PI3Ks orchestrate several cellular responses for host defense, including PMN ROS generation (12). Befitting its central role in cell activation, several mechanisms are in place to restrain PI3K activity (16-18). Previous reports have suggested a link between decreased PIPP formation and increased PI3K $(19,20)$. Results presented here are the first to demonstrate direct inhibition of PI3K by a PIPP and inverse relationships between PI3K 
A

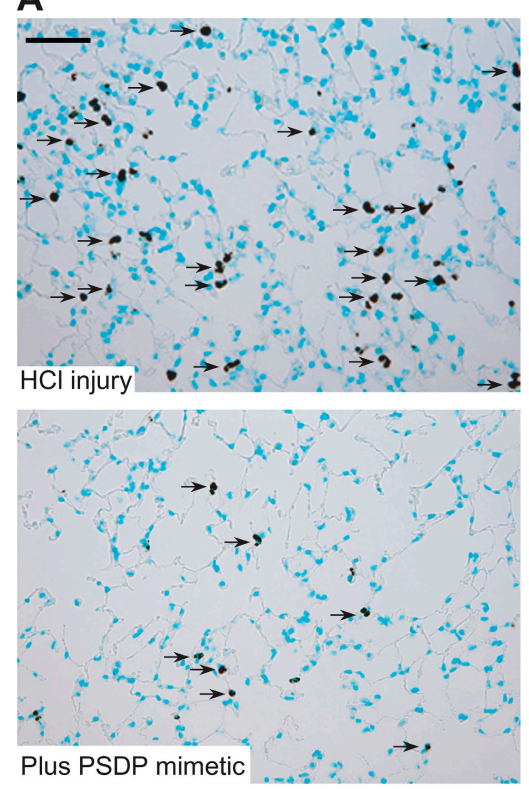

Figure 5. PSDP reduced acid-initiated ALI. (A) PSDP structural mimetic ( $0.8 \mu \mathrm{g} /$ mouse) or vehicle was administered (i.v.) $15 \mathrm{~min}$ before $\mathrm{HCl}$ injury. $12 \mathrm{~h}$ after $\mathrm{HCl}$ instillation, histological specimens were prepared and mouse PMN were identified by LY-6G immunostaining (arrows). Bar, $100 \mu \mathrm{m}$. (B) Tissue morphometry was performed to determine

activity and PSDP levels both in vitro and in vivo. In addition, PSDP bound to $110 \gamma-\mathrm{PI} 3 \mathrm{~K}$ in activated PMN and potently inhibited rhp110 $\gamma$-PI3K in vitro and a PSDP structural mimetic blocked PI3K activity in vivo. Together, these new findings support a signaling relationship between PI3K and PIPPs in the regulation of leukocyte functions during inflammation.

Pivotal regulatory properties have been ascribed to isoprenoids. For example, polyisoprenyl glycolipids form antigen complexes with CD1 to activate $\mathrm{T}$ cells (21), and cholesterol is critical to PMN cell membrane organization and polarization in response to chemotactic stimuli (22). Although PIPPs are appreciated as cholesterol biosynthetic intermediates, PSDP is also present in cells, such as human PMN, that cannot use it for cholesterol biosynthesis because they lack squalene cyclase and other mixed function oxidase activities (23). There are now several lines of evidence to support a role for PSDP as a counterregulatory signal in PMN functional responses. PSDP is a constituent of PMN cell membranes (20), and receptor activation leads to rapid and transient PIPP remodeling. PSDP is a potent and direct inhibitor of phospholipase D (PLD) with at least two interaction domains on human PLD1b for PSDP (8). PSDP also interacts with Src-homology 2 (SH2) domains on the adaptor protein Grb2 (24) and blocks NADPH oxidase assembly in a cell-free assay (6). PSDP displays anti-PMN properties in vitro and in vivo, and PSDP structural mimetics are able to dampen leukocyte-driven inflammation (8). Here, we have identified PI3K as a new target for regulation by PSDP. The
B

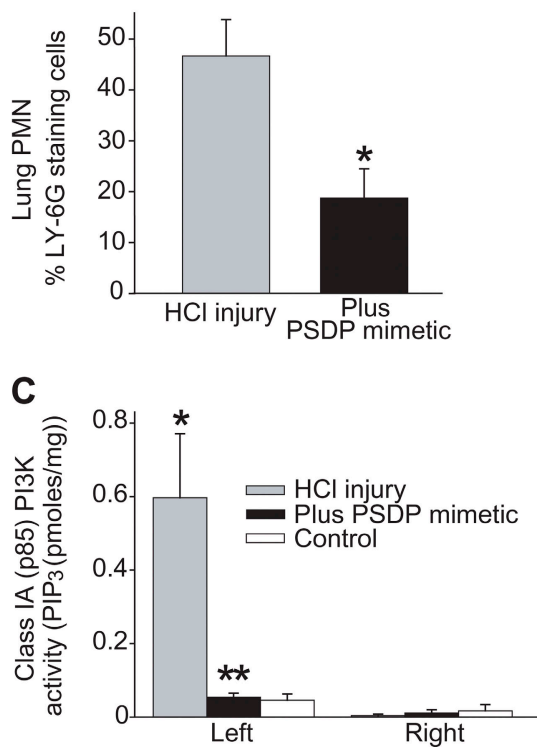

the percentage of $L Y-6 G$ staining cells in mouse lungs ( $n=4$ measurements in each group; ${ }^{*}, \mathrm{P}<0.05$ as compared with $\mathrm{HCl}$-injured left lung). (C) Class IA (p85-based) PI3K activity was determined in lung lysates after ALI. Data are mean \pm SEM. $n=3 ;{ }^{*}, P<0.05$ as compared with control; ${ }^{*}, \mathrm{P}<0.05$ as compared with $\mathrm{HCl}$-injured lung.

physical interaction between PI3K and PSDP and absence of regulatory proteins in our in vitro system indicate that PSDP can directly inhibit p110 $\gamma-$ PI3K. Similar to PLD (8), the diphosphate moiety of PSDP was also important for PI3K inhibition, and the stoichiometry suggests multiple potential sites for PSDP and PI3K interaction. Both class IA and IB PI3Ks translocate to membranes via interactions with Ras that is activated, in part, via isoprenylation (25). These shared isoprenoid moieties with PSDP may provide additional sites of interaction outside the PI3K catalytic center. Of interest, PSDP and PI3K are present in resting PMN in complementary intracellular locations (cell membranes and cytosol, respectively), and both translocate to intracellular organelles upon cell activation $(20,26)$.

Activated PMN contribute to the development and severity of tissue injury during inflammatory illnesses such as ALI. No specific therapy is currently available to modulate the inflammatory response to airway injury from acid and protect the lung in ALI. PI3K is an important enzyme in the proinflammatory PMN signaling program of ALI, as p110 $\gamma-$ PI3K deficiency dampens the severity of endotoxin-induced ALI (13). In addition to PMN, PI3Ks are also activated during ALI in lung-resident cells (27) and both endothelial cell and PMN PI3Ks contribute to PMN accumulation in the lung (28). Select lipid mediators, namely lipoxin $\mathrm{A}_{4}\left(\mathrm{LXA}_{4}\right)$, inhibit PI3K in structural cells (29). $\mathrm{LXA}_{4}$ signaling also promotes resolution of experimental ALI (15) and inhibits PMN activation by $\mathrm{LTB}_{4}$ in a postreceptor manner, in part by blocking PSDP remodeling (7). Here, PSDP levels were 
decreased in acid-injured lungs and a novel PSDP mimetic blocked PI3K, PMN ROS generation, and PMN accumulation in the lung. Because the PSDP mimetic was administered intravenously, regulation of cells other than PMN may have also contributed to the marked inhibition of leukocyte trafficking after acid injury.

In conclusion, the ability of PSDP and a new PSDP mimetic to directly inhibit PMN early intracellular activating signals, such as PI3K, and to lessen the inflammation associated with experimental ALI provides insight into new mechanisms for in vivo protection from excess PMN-driven inflammation and tissue injury. Together, our findings suggest that PIPP signaling pathways, and specifically PSDP, can serve as natural templates for the design of new therapeutic strategies in inflammatory diseases.

\section{MATERIALS AND METHODS}

Materials. PSDP and PSMP were isolated from human PMN or prepared by total organic synthesis (8). The bisphosphonate PSDP structural mimetic, tetraethyl presqualene carboxamido-methylene-diphosphonate was prepared from presqualene carboxylic acid. All synthetic compounds were characterized by NMR spectroscopy.

Human PMN incubations. Peripheral blood was obtained by venipuncture from healthy volunteers who denied taking any medications for at least $2 \mathrm{wk}$ and had given written informed consent to a protocol approved by Brigham and Women's Hospital's Human Research Committee. PMN were isolated from whole blood as described previously (6). Freshly isolated PMN $\left(1-5 \times 10^{6} \mathrm{PMN} / \mathrm{ml}\right.$ HBSS plus $\left.1.6 \mathrm{mM} \mathrm{CaCl}_{2}\right)$ were incubated $\left(5 \mathrm{~min}, 37^{\circ} \mathrm{C}\right.$ ) in the presence of $3 \mu \mathrm{M} \mathrm{LY} 294002,100 \mathrm{nM}$ PSDP mimetic, or vehicle $\left(0.1 \%\right.$ ethanol), then exposed to $\mathrm{LTB}_{4}(100 \mathrm{nM})$ in the presence of $7 \mathrm{mg} / \mathrm{ml}$ cytochrome $\mathrm{c}$. This concentration of $\mathrm{LTB}_{4}$ was chosen because it initiates PMN NADPH oxidase assembly (7) and is similar to amounts measured in vivo at sites of acute inflammation (30). In some incubations, PMN in HBSS without calcium were exposed to PSDP mimetic or vehicle, pelleted by centrifugation $(700 \mathrm{~g}, 3 \mathrm{~min}$ ), and resuspended in HBSS plus $1.6 \mathrm{mM} \mathrm{CaCl} 2$ without PSDP before the addition of agonist. Superoxide anion generation was determined $\left(37^{\circ} \mathrm{C}\right)$ as superoxide dismutase-inhibitable cytochrome $\mathrm{c}$ reduction by monitoring $(550 \mathrm{~nm})$ at 5 -s intervals in a continuously flowing water-bath-jacketed cassette or after timed incubations. For PSDP identification, PMN $\left(50-100 \times 10^{6}\right.$ cells $\left./ \mathrm{ml}\right)$ were activated $\left(\mathrm{LTB}_{4}\right.$ $100 \mathrm{nM}, 30 \mathrm{~s}$ ) before disruption by $\mathrm{N}_{2}$ cavitation $\left(350 \mathrm{psi}, 20 \mathrm{~min}, 4^{\circ} \mathrm{C}\right)$. Remaining intact cells and nuclei were pelleted $\left(500 \mathrm{~g}, 10 \mathrm{~min}, 4^{\circ} \mathrm{C}\right)$ and supernatants were used for immunoprecipitation with anti-p110 $\gamma-$ PI3K $\left(4^{\circ} \mathrm{C}\right)$. After overnight incubation, washed protein $\mathrm{A}$ agarose $(60 \mu \mathrm{l})$ was added and incubated for $2 \mathrm{~h}$ at $4^{\circ} \mathrm{C}$. After several washes, the immunoprecipitates were saponified, lipids were extracted, and materials were analyzed by GC/MS (Hewlett-Packard) (6). Injections in $2-5 \mu \mathrm{CHCl}_{3}$ were made onto a fused-silica capillary DB-17 column (30 mm, $0.25 \mathrm{~mm}$ i.d.) obtained from J\&W. Scientific with helium as carrier gas and a column temperature program $\left(150-260^{\circ} \mathrm{C}\right.$ at $15^{\circ} \mathrm{C}$ per $\left.\min ^{-1}\right)$.

Measurement of class IA and IB PI3K activity. After immunoprecipitation with either an anti-p 85 or anti-p110 $\gamma$-PI3K selective antibody, PI3K activity from PMN and lung homogenates was determined by $\mathrm{PIP}_{3}$ formation in vitro using a competitive ELISA (Echelon Biosciences Inc.). For recombinant purified PI3K enzyme, activity was determined by a luminescent kinase assay (Kinase-Glo; Promega) that quantitated decrements in ATP by kinase utilization. rh p110 $\gamma$-PI3K (4 pmol/reaction) was exposed $\left(15 \mathrm{~min}, 37^{\circ} \mathrm{C}\right)$ to PSDP or PSMP $(0.4-800 \mathrm{pmol})$ followed by $25 \mu \mathrm{g}$ $\mathrm{L}-\alpha$-phosphatidylinositol and $1 \mu \mathrm{M}$ ATP and allowed to react for $90 \mathrm{~min}$ at room temperature. Incubations were stopped with $50 \mu$ l of KinaseGlo reagent and incubated an additional $10 \mathrm{~min}$ at room temperature.
Luminescence was measured with a FLx800 microplate luminometer (BioTek Instruments, Inc.).

Experimental model of ALI. All animal protocols were approved by the Harvard Medical Area Animal Institutional Review Board. Acid $(0.1 \mathrm{~N} \mathrm{HCl}$, $\mathrm{pH}=1.5,50 \mu \mathrm{l})$ was instilled intratracheally into the left lung of anesthetized mice (FVB, male, 10-12 wk; Charles River Laboratories) (15). A PSDP mimetic ( $0.8 \mu \mathrm{g}$ in $100 \mu \mathrm{l} 0.9 \%$ saline) or vehicle ( $1 \%$ ethanol) was administered by tail vein $15 \mathrm{~min}$ before $\mathrm{HCl}$ instillation. After $12 \mathrm{~h}$, lungs were removed, prepared for MPO (15) or PI3K assay, or were fixed in IHC zinc buffer and paraffin embedded for immunostaining with LY-6G (1:50 dilution). Area and number of positively staining cells was measured with National Institutes of Health Image software and percentage of positive cells/area calculated.

Statistical analysis. Results are expressed as the mean \pm SEM. Statistical significance of differences was assessed by Student's $t$ test and one-way analysis of variance. $\mathrm{P}<0.05$ was set as the level of significance.

Online supplemental material. Fig. S1 shows the CMC determination for the PSDP mimetic and related compounds. Further information on materials and experimental protocols are supplied as the supplemental Materials and methods. Online supplemental material is available at http://www.jem. org/cgi/content/full/jem.20052143/DC1.

The authors would like to acknowledge the contributions of Dr. C.N. Serhan to the development of the PSDP mimetic and for his critical review of the manuscript. We also thank Dr. M.A. Perrella and members of the Brigham and Women's Hospital Lung Biology Center and Histopathology Core Laboratory for their assistance with the experimental models of ALI.

This work was supported in part by the NIH (HL68669 and NIDCR Specialized Research Center grant no. DE016191), and fellowships from La Fondation de la Recherche Médicale, Pfizer, and Uehara Memorial Research Foundation.

The authors have no conflicting financial interests.

Submitted: 24 October 2005

Accepted: 27 February 2006

\section{REFERENCES}

1. Nathan, C. 2002. Points of control in inflammation. Nature. 420: 846-852.

2. Weiss, S.J. 1989. Tissue destruction by neutrophils. N. Engl. J. Med. 320: 365-376.

3. Ware, L.B., and M.A. Matthay. 2000. The acute respiratory distress syndrome. N. Engl. J. Med. 342:1334-1349.

4. Gilroy, D.W., T. Lawrence, M. Perretti, and A.G. Rossi. 2004. Inflammatory resolution: new opportunities for drug discovery. Nat. Rev. Drug Discov. 3:401-416.

5. Drenth, J.P.H., and J.W.M. van der Meer. 2001. Hereditary periodic fever. N. Engl. J. Med. 345:1748-1757.

6. Levy, B.D., N.A. Petasis, and C.N. Serhan. 1997. Polyisoprenyl phosphates in intracellular signalling. Nature. 389:985-990.

7. Levy, B.D., V.V. Fokin, J.M. Clark, M.J. Wakelam, N.A. Petasis, and C.N. Serhan. 1999. Polyisoprenyl phosphate (PIPP) signaling regulates phospholipase D activity: a 'stop' signaling switch for aspirin-triggered lipoxin A 4. FASEB J. 13:903-911.

8. Levy, B.D., L. Hickey, A.J. Morris, M. Larvie, R. Keledjian, N.A. Petasis, G. Bannenberg, and C.N. Serhan. 2005. Novel polyisoprenyl phosphates block phospholipase D and human neutrophil activation in vitro and murine peritoneal inflammation in vivo. Br. J. Pharmacol. 146:344-351.

9. Karlsson, A., J.B. Nixon, and L.C. McPhail. 2000. Phorbol myristate acetate induces neutrophil NADPH-oxidase activity by two separate signal transduction pathways: dependent or independent of phosphatidylinositol 3-kinase. J. Leukoc. Biol. 67:396-404.

10. Ito, N., T. Yokomizo, T. Sasaki, H. Kurosu, J. Penninger, Y. Kanaho, T. Katada, K. Hanaoka, and T. Shimizu. 2002. Requirement of phosphatidylinositol 3-kinase activation and calcium influx for leukotriene B4-induced enzyme release. J. Biol. Chem. 277:44898-44904. 
11. Scott, C.C., W. Dobson, R.J. Botelho, N. Coady-Osberg, P. Chavrier, D.A. Knecht, C. Heath, P. Stahl, and S. Grinstein. 2005 Phosphatidylinositol-4,5-bisphosphate hydrolysis directs actin remodeling during phagocytosis. J. Cell Biol. 169:139-149.

12. Hirsch, E., V.L. Katanaev, C. Garlanda, O. Azzolino, L. Pirola, L. Silengo, S. Sozzani, A. Mantovani, F. Altruda, and M.P. Wymann. 2000. Central role for $G$ protein-coupled phosphoinositide 3-kinase gamma in inflammation. Science. 287:1049-1053.

13. Yum, H.K., J. Arcaroli, J. Kupfner, R. Shenkar, J.M. Penninger, T. Sasaki, K.Y. Yang, J.S. Park, and E. Abraham. 2001. Involvement of phosphoinositide 3-kinases in neutrophil activation and the development of acute lung injury. J. Immunol. 167:6601-6608.

14. Serhan, C.N., M.J. Broekman, H.M. Korchak, A.J. Marcus, and G. Weissmann. 1982. Endogenous phospholipid metabolism in stimulated neutrophils differential activation by FMLP and PMA. Biochem. Biophys. Res. Commun. 107:951-958.

15. Fukunaga, K., P. Kohli, C. Bonnans, L.E. Fredenburgh, and B.D. Levy. 2005. Cyclooxygenase 2 plays a pivotal role in the resolution of acute lung injury. J. Immunol. 174:5033-5039.

16. Gout, I., G. Middleton, J. Adu, N.N. Ninkina, L.B. Drobot, V. Filonenko, G. Matsuka, A.M. Davies, M. Waterfield, and V.L. Buchman. 2000. Negative regulation of PI 3-kinase by Ruk, a novel adaptor protein. EMBO J. 19:4015-4025.

17. Harrington, L.S., G.M. Findlay, and R.F. Lamb. 2005. Restraining PI3K: mTOR signalling goes back to the membrane. Trends Biochem. Sci. 30:35-42.

18. Kwak, Y.G., C.H. Song, H.K. Yi, P.H. Hwang, J.S. Kim, K.S. Lee, and Y.C. Lee. 2003. Involvement of PTEN in airway hyperresponsiveness and inflammation in bronchial asthma. J. Clin. Invest. 111:1083-1092.

19. Dimmeler, S., A. Aicher, M. Vasa, C. Mildner-Rihm, K. Adler, M. Tiemann, H. Rutten, S. Fichtlscherer, H. Martin, and A.M. Zeiher. 2001. HMG-CoA reductase inhibitors (statins) increase endothelial progenitor cells via the PI 3-kinase/Akt pathway. J. Clin. Invest. 108: 391-397.

20. Levy, B.D., and C.N. Serhan. 2000. Polyisoprenyl phosphate signaling: topography in human neutrophils. Biochem. Biophys. Res. Commun. 275 739-745.
21. Moody, D.B., M.R. Guy, E. Grant, T.Y. Cheng, M.B. Brenner, G.S. Besra, and S.A. Porcelli. 2000. CD1b-mediated T cell recognition of a glycolipid antigen generated from mycobacterial lipid and host carbohydrate during infection. J. Exp. Med. 192:965-976.

22. Pierini, L.M., R.J. Eddy, M. Fuortes, S. Seveau, C. Casulo, and F.R. Maxfield. 2003. Membrane lipid organization is critical for human neutrophil polarization. J. Biol. Chem. 278:10831-10841.

23. Shechter, I., A.M. Fogelman, and G. Popjak. 1980. A deficiency of mixed function oxidase activities in the cholesterol biosynthetic pathway of human granulocytes. J. Lipid Res. 21:277-283.

24. Levy, B.D., and C.N. Serhan. 2003. Polyisoprenyl phosphates: natural antiinflammatory lipid signals. Cell. Mol. Life Sci. 59:1-13.

25. Philips, M.R., M.H. Pillinger, R. Staud, C. Volker, M.G. Rosenfeld, G. Weissmann, and J.B. Stock. 1993. Carboxyl methylation of Rasrelated proteins during signal transduction in neutrophils. Science. 259 977-980.

26. Yu, W., J. Cassara, and P.F. Weller. 2000. Phosphatidylinositide 3-kinase localizes to cytoplasmic lipid bodies in human polymorphonuclear leukocytes and other myeloid-derived cells. Blood. 95:1078-1085.

27. Uhlig, U., H. Fehrenbach, R.A. Lachmann, T. Goldmann, B. Lachmann, E. Vollmer, and S. Uhlig. 2004. Phosphoinositide 3-OH kinase inhibition prevents ventilation-induced lung cell activation. Am. J. Respir. Crit. Care Med. 169:201-208.

28. Puri, K.D., T.A. Doggett, J. Douangpanya, Y. Hou, W.T. Tino, T. Wilson, T. Graf, E. Clayton, M. Turner, J.S. Hayflick, and T.G. Diacovo. 2004. Mechanisms and implications of phosphoinositide 3kinase $\delta$ in promoting neutrophil trafficking into inflamed tissue. Blood. 103:3448-3456

29. McMahon, B., C. Stenson, F. McPhillips, A. Fanning, H.R. Brady, and C. Godson. 2000. Lipoxin A4 antagonizes the mitogenic effects of leukotriene D4 in human renal mesangial cells. Differential activation of MAP kinases through distinct receptors. J. Biol. Chem. 275: 27566-27575.

30. Klein, A., A. Talvani, D.C. Cara, K.L. Gomes, N.W. Lukacs, and M.M. Teixeira. 2000. Stem cell factor plays a major role in the recruitment of eosinophils in allergic pleurisy in mice via the production of leukotriene B4. J. Immunol. 164:4271-4276. 